\title{
Risk and protective factors for psychological distress during COVID-19 in Israel
}

\author{
Zohar Oryan $^{1} \cdot$ Asia Avinir $^{1} \cdot$ Sigal Levy $^{1} \cdot$ Einat Kodesh $^{2} \cdot$ Odelia Elkana $^{1}$ (D) \\ Accepted: 21 June 2021 / Published online: 5 July 2021 \\ (C) The Author(s), under exclusive licence to Springer Science+Business Media, LLC, part of Springer Nature 2021
}

\begin{abstract}
The purpose of the present study was to identify the protective and risk factors related to psychological distress during COVID-19 in an Israeli sample. An online survey was administered from April 19 to May 2, 2020, while a strict lockdown was in place. Participants were recruited by snowball sampling. Psychological distress was evaluated using the Generalized Anxiety Disorder questionnaire (GAD-7) and the Patient Health Questionnaire-9 (PHQ-9). Risk and protective factors for psychological distress were assessed on the Multi-dimensional Perceived Social Support (MSPSS), the coping strategies (COPE), the Life Orientation Test (LOT), and the Gratitude questionnaire. Out of the 655 valid questionnaires collected (from participants ranging in age from 18 to 86, 246 males, 409 females), 138 (21.3\%) were positive for moderate to very severe depression and 87 (13.2\%) for moderate to extremely severe anxiety. Participants who were screened for depression and anxiety were more likely to be women and young adults (18-24). After adjusting statistically for gender, age, and socioeconomic status, depression and anxiety remained significantly associated with both emotion-focused (PHQ- $\beta=.437, p<.001$, GAD- $\beta=.441, p<.001$ ) and problemfocused (PHQ- $\beta=-.219, p<.001$, GAD- $\beta=-.143, p<.001$ ) coping strategies, as well as on the social support (PHQ- $\beta=-.167, p$ $<.001$, GAD- $\beta=-.155, p<.001$ ), life orientation (GAD- $\beta=-.09, p<.001$ ), and gratitude scales (PHQ- $\beta=-.07, p<.001$ ). Levels of anxiety and depression were generally associated with gender (women), age (younger population), socioeconomic status (low), and an emotion-focused strategy as risk factors. A problem-focused strategy, social support, life orientation, and gratitude served as protective factors above and beyond personal background.
\end{abstract}

Keywords COVID-19 $\cdot$ Depression $\cdot$ Anxiety $\cdot$ Coping strategies $\cdot$ Risk factor $\cdot$ Protective factor $\cdot$ Psychological distress $\cdot$ Social support $\cdot$ Life orientation

\section{Introduction}

Psychological distress (i.e., depression and anxiety) has a substantial negative impact on daily life, including high morbidity

Odelia Elkana

odelia.elkana@gmail.com

Zohar Oryan

zoharoryan92@gmail.com

Asia Avinir

asiavinir@gmail.com

Sigal Levy

levy@mta.ac.il

Einat Kodesh

ekodesh@gmail.com

1 Behavioral Sciences, Academic College of Tel Aviv-Yafo, P.O.B 8401, 61083 Tel Aviv, Jaffa, Israel

2 Physical Therapy Department, University of Haifa, Haifa, Israel and mortality (Mykletun et al., 2007; Hidaka, 2012; Chesney et al., 2014). This underscores the urgent need to identify the risks as well as the protective factors that increase or decrease the likelihood of distress. To date, these factors have rarely been measured during a national and/or an international crisis (Hobfoll et al., 1989; Zeidner \& Ben-Zur, 1993; Cheng \& Tang, 2004; Bleich et al., 2006).

Several sociodemographic risk factors associated with psychological distress have been identified and documented in everyday life. Gender (women) (Johansson et al., 2013; Hinz \& Brähler, 2011), age (older population) (Hinz \& Brähler, 2011; Hinz \& Schwarz, 2001; Stordal et al., 2001), and socioeconomic status (low status) (Wang et al., 2010; Hudson et al., 2012) have all been found to be related to higher levels of depression and anxiety.

Coping strategies play a key role in reducing psychological distress. According to Lazarus (1984), coping is the way in which individuals respond to a particular threat after a cognitive appraisal. These responses may vary and thus correspond to different coping strategies. In general, a failure to adaptively 
cope with stress may lead to mental health problems (Folkman \& Lazarus, 1984). Emotion-focused coping is a strategy aimed to reduce the emotional burden without changing the stressor or the problem. Here, individuals modify the personal or internal meaning of the stressful situation or relationship (Lazarus, 1999). The findings on the effectiveness of this strategy are mixed, with some studies reporting increased, and others reporting decreased distress (Christensen \& Kessing, 2005; Salehi et al., 2013; Roohafza et al., 2016). This may be related to the nature of emotion-focused coping, which encompasses a broad range of coping strategies, each with a varying degree of success, depending on the specific situation (Baker \& Berenbaum, 2007; Van Berkel, 2009). By contrast, problem-focused coping attempts to modify the situation by gathering information and taking task-oriented steps to develop practical plans for dealing with the stressor or the problem (Folkman \& Moskowitz, 2000; Matthieu \& Ivanoff, 2006). Problem-focused coping has generally been related to reduced psychological distress and better adaptation to stressful experiences, thus making it a protective factor (Christensen \& Kessing, 2005; Van Berkel, 2009; Bozo et al., 2018).

Several other protective factors have been identified. One of the main factors is social support. Most definitions of social support are based on Cobb (1976): "Social support is defined as information leading the subject to believe that he is cared for and loved, esteemed and a member of a network of mutual obligations." Social support can be emotional (e.g., deriving from a sense of affection, belonging, confidence) or instrumental (e.g., getting practical help, advice, money), as cited in Grav, Hellzèn, Romild, and Stordal (Grav et al., 2012). It is considered to directly safeguard mental health by leveraging the benefits of social interactions while indirectly shielding against stressful circumstances (Gariepy et al., 2016; McGuire et al., 2018; Viseu et al., 2018). It is thought that social support functions as an interpersonal emotional regulation that enables adaptive coping with stressors (Marroquín, 2011). For example, Grav, Hellzèn, Romild, and Stordal (Grav et al., 2012) showed how the risk of depression increased in participants who lacked sufficient social support. The two other key protective factors cited in the literature are gratitude and optimism. Gratitude, as a trait, is reflected in the ability to be aware of positive things in life. It is manifested in an appreciation of what one is fortunate to have and in thankfulness to others (Wood et al., 2008; Wood et al., 2011). Studies have shown that participants who experienced gratitude were more resilient to trauma-related stress and coped better with day-to-day stress. They also recovered more quickly from illness and enjoyed better physical health (Sirois \& Wood, 2017; Emmons \& Stern, 2013; Lambert et al., 2012). Optimism is defined as a relatively stable generalized tendency to expect positive rather than negative life outcomes (Scheier \& Carver, 1985). Participants who reported higher levels of optimism were found to be more resilient to stress and more likely to use adaptive coping strategies (Conversano et al., 2010).

The current study examined the role of these factors in relation to the COVID-19 pandemic, which has generated major psychological challenges (Zhang et al., 2020; Rajkumar, 2020; Huang \& Zhao, 2020; Losada-Baltar et al., 2020). For example, Wang et al. examined the immediate psychological responses during the initial stage of the pandemic in China and found that in the general population, $16.5 \%$ reported moderate to severe depressive symptoms, and $28.8 \%$ reported moderate to severe anxiety symptoms (Wang et al., 2020).

Several studies have investigated the impact of a number of factors mentioned above during the current COVID-19 pandemic. Similar to findings for non-crisis periods, lack of social support, low socioeconomic status, and being a female have been found to be related to a higher risk of depression and anxiety (Huang \& Zhao, 2020; Losada-Baltar et al., 2020; Wang et al., 2020; Qiu et al., 2020; Cao et al., 2020). However, in terms of age, younger individuals were reported to be at greater risk of displaying symptoms of depression or anxiety during the current pandemic (Huang \& Zhao, 2020; Losada-Baltar et al., 2020), as compared to non-crisis eras. Qiu et al. (Qiu et al., 2020) suggested that stress in young people is triggered by the massive amount of media information they consume as compared to older adults.

However, other factors such as coping strategies, gratitude, and optimism have yet to be examined during the current COVID-19 pandemic. The present study examined whether factors that are considered to be either protective or risk factors with respect to depression and anxiety in daily life functioned as such during the current COVID-19 pandemic. It also examined the contribution of each of these factors to depression and anxiety during the mid-stages of the first wave of the pandemic in Israel. It was hypothesized that social support, optimism, and gratitude would act as protective factors against depression and anxiety. However, due to the massive uncertainty associated with this period of time, and the inconclusiveness of the findings as to the effectiveness of some coping strategies, analyses related to the impact of coping strategies style on depression and anxiety can only be exploratory.

\section{Method}

Digital questionnaires were administered on a Qualtrics ${ }^{X M}$ (https://www.qualtrics.com/) platform. These included a demographic questionnaire (Appendix), the Generalized Anxiety Disorder (GAD), the Patient Health Questionnaire (PHQ), the Multi-dimensional Perceived Social Support (MSPSS), the brief coping strategies (COPE), the Life Orientation Test (LOT), and the Gratitude questionnaire, all of which are detailed below. These questionnaires were sent to 
participants' emails or phone apps throughout Israel via a snowball sampling method. To protect the participants' anonymity, no personal information and no IP addresses were collected, so that there would not be a way to link respondents and identities. In addition, the questionnaire was blocked after it was submitted. Nevertheless, the possibility that respondents completed the questionnaire from different devices cannot be ruled out, thus inflating the sample size.

\section{Participants}

A total of 655 participants, aged $18-86$, were included in this study. Two hundred participants did not complete the questionnaires. Of these, $45 \%$ did not complete the sociodemographic questions. Of the $55 \%$ remaining participants, only $1.3 \%$ completed the GAD-7 and PHQ-9 questionnaires. Since depression and anxiety were the main focus of this study, a missing data analysis was not conducted. The inclusion criteria were individuals over the age of 18, who were fluent in Hebrew. Participants who failed to complete all the questionnaires were excluded.

\section{Procedure}

The Ethics Committee of Academic College of Tel AvivYafo, Israel, approved the experimental procedure (approval number 2020085), and all participants signed an electronic informed consent form allowing access to the full set of questionnaires. Once participants signed the consent form, they were asked to complete the questionnaires online.

Responses to questionnaires were obtained over a period of 8 days between April 19 and May 2, 2020, while the State of Israel was experiencing the peak of the first wave of COVID19. During this time, strict regulations were implemented for 3 weeks, including government shelter in place orders and the banning of social gatherings. During this time, the average number of reported positive COVID-19 cases was 15,195, with a notable increase of 2259 more positive reported cases toward the end, which represents $0.02 \%$ of the population of Israel. The first positive COVID-19 case recorded in Israel was reported at end of February 2020.

\section{Measures}

\section{Demographic Information}

The demographic variables included the participants' age, gender, and socioeconomic status (Table 1). The socioeconomic status index was composed of the average score of three questions presented to the participants (questions 5, 7, and 20 in Appendix) assessing level of education (participants who answered "other" were excluded), subjective perception of socioeconomic status (participants who responded "low- average" were grouped with participants who checked "low," due to the low prevalence of both groups), and financial resources for the next 3 months (participants who responded "enough" were grouped with participants who responded "my resources will suffice for the next three months but not for a year"). The composite index ranged from 1 to 4 , such that higher values referred to higher socioeconomic status. Thus, the socioeconomic composite score provided an approximate but robust measure of the socioeconomic status of the participants.

\section{Anxiety}

The Generalized Anxiety Disorder questionnaire is a selfreport questionnaire that assesses symptoms of anxiety based on the Diagnostic and Statistical Manual of Mental DisordersIV (Löwe et al., 2008). The questionnaire administered was the Hebrew version of the GAD-7 scale devised by Spitzer, Kroenke, Williams, and Lowe (Spitzer et al., 2006). It contains 7 items, in which the participants are asked to state the extent to which a sentence describes them in the last 2 weeks, on a scale ranging from 0 (not at all to) to 3 (almost every day). For example, a sample item is "worrying too much about different things." The GAD-7 items are scored from 0 to 21, with scores of $\geq 5, \geq 10$, and $\geq 15$ representing mild, moderate, and severe anxiety symptom levels, respectively. The reliability of the questionnaire as reported by the developers was found to be high (Cronbach $\alpha=$.92) (Löwe et al., 2008). A total score of $\geq 9$ was defined in this study as anxiety (Newman et al., 2002). The internal consistency in the current sample was $\alpha=0.892$.

\section{Depression}

Level of depression was assessed on the Patient Health Questionnaire-9 (PHQ-9) (Spitzer et al., 1999), a 9-item depression module taken from the full PHQ questionnaire (Kroenke et al., 2001). For example, a sample item is "feeling down, depressed, or hopeless." Responses range from 0 (not at all) to 3 (nearly every day) This questionnaire was translated into Hebrew and validated (Geulayov et al., 2009). Scores of $\geq 5, \geq 10, \geq 15$, and $\geq 20$ represent mild, moderate, moderately severe, and severe depression, respectively. A total score of $\geq 10$ was defined in this study as depression (Manea et al., 2012). The Cronbach's alpha as reported by the developers was .89 and .86 in the validation studies of the PHQ-9 (Spitzer et al., 1999). In the current sample, the internal consistency was $\alpha=.84$.

\section{Social Support}

The Multi-dimensional Perceived Social Support scale is a self-report questionnaire that examines a person's subjective 
Table 1. Demographic characteristics $(\mathrm{N}=655)$

\begin{tabular}{|c|c|c|}
\hline & $\mathrm{N}$ & $\%$ \\
\hline \multicolumn{3}{|l|}{ Gender } \\
\hline Male & 246 & $37.4 \%$ \\
\hline Female & 409 & $62.6 \%$ \\
\hline \multicolumn{3}{|l|}{ Age } \\
\hline $18-24$ & 122 & $18.6 \%$ \\
\hline $25-39$ & 312 & $47.5 \%$ \\
\hline $40-59$ & 145 & $22.1 \%$ \\
\hline $60-86$ & 76 & $11.6 \%$ \\
\hline \multicolumn{3}{|l|}{ Level of education } \\
\hline 12 years of education or less, without diploma & 23 & $3.5 \%$ \\
\hline 12 years of education or less, with diploma & 125 & $19.1 \%$ \\
\hline B.A. & 295 & $45 \%$ \\
\hline M.A. (or higher) & 187 & $28.5 \%$ \\
\hline Other & 25 & $3.8 \%$ \\
\hline \multicolumn{3}{|l|}{ Perceived socioeconomic status } \\
\hline Low & 21 & $3.2 \%$ \\
\hline Low-average & 79 & $12.1 \%$ \\
\hline Average & 281 & $42.9 \%$ \\
\hline Average-high & 224 & $34.2 \%$ \\
\hline High & 50 & $7.6 \%$ \\
\hline \multicolumn{3}{|l|}{ Financial resources for the next 3 months } \\
\hline Not enough at all & 60 & $9.2 \%$ \\
\hline Hardly enough & 97 & $14.8 \%$ \\
\hline Enough & 233 & $35.6 \%$ \\
\hline Definitely enough & 208 & $31.8 \%$ \\
\hline My resources will suffice for the next 3 months but not for a year & 57 & $8.7 \%$ \\
\hline \multicolumn{3}{|l|}{ Composite index of socioeconomic status } \\
\hline Low & 46 & $7.1 \%$ \\
\hline Average & 309 & $47.3 \%$ \\
\hline Average-high & 281 & $42.9 \%$ \\
\hline High & 19 & $2.9 \%$ \\
\hline \multicolumn{3}{|l|}{ Health status } \\
\hline Healthy & 616 & $94 \%$ \\
\hline Healthy in quarantine & 27 & $4.1 \%$ \\
\hline Diagnosed with COVID-19 currently in quarantine & 1 & $0.2 \%$ \\
\hline Suffers from another disease & 11 & $1.7 \%$ \\
\hline \multicolumn{3}{|l|}{ Occupational status after the outbreak of COVID-19 } \\
\hline Full-time job & 201 & $30.7 \%$ \\
\hline Partially employed & 168 & $25.6 \%$ \\
\hline Unpaid vacation & 156 & $23.8 \%$ \\
\hline Lost job & 10 & $1.5 \%$ \\
\hline Unemployed & 82 & $12.5 \%$ \\
\hline Retired & 38 & $5.8 \%$ \\
\hline \multicolumn{3}{|l|}{ Media consumption per day } \\
\hline None at all & 60 & $9.2 \%$ \\
\hline 1 hour or less & 312 & $47.6 \%$ \\
\hline $1-2$ hours & 163 & $24.9 \%$ \\
\hline $2-3$ hours & 72 & $11 \%$ \\
\hline More than 3 hours & 48 & $7.3 \%$ \\
\hline
\end{tabular}


perception of the extent of his or her social support. The questionnaire administered was the Hebrew version of the Multidimensional Perceived Social Support (MSPSS) developed by Zimet, Dahlem, Zimet, and Farley. The reliability of the questionnaire as reported by the original authors was high (Cronbach $\alpha=.85$ ) (Zimet et al., 1988). It contains 12 items divided into three subscales: family, friends, and significant others. For example, in the family scale, a sample item is "I can talk about my problems with my family"; a sample item for the friends' scale is "I can count on my friends when things go wrong"; and a sample item for significant others scale is "There is a special person in my life who cares about my feelings." The participants are asked to rate the extent to which they relate to each item from 0 (not at all) to 7 (very much). Subscale scores are obtained by averaging the items, with higher scores indicating higher perceived social support.

\section{Coping Strategies}

The coping strategies (COPE) is a self-report questionnaire that examines how a person would deal with stressful and negative events. The questionnaire is a short form of the COPE scale developed by Craver, Scheier, and Weintraub (Carver et al., 1989) and translated into Hebrew by Ben-Zur and Zeidner (Ben-Zur \& Zeidner, 1995). It contains 15 subscales, each represented by two out of four items in the original scale, and is computed as an unweighted sum of responses to the 2 items that make up that scale. Responses range from 0 (not at all) to 5 (very much). The subscales are active coping, planning, seeking instrumental social support, seeking emotional social support, suppression of competing activities, religion, positive reinterpretation, restraint coping, acceptance, ventilation of emotion, denial, mental disengagement, behavioral disengagement, alcohol and drug use, and humor. The coping dimensions can also be divided into two major categories: problem-focused strategies (i.e., active coping, planning, and using instrumental support) and emotion-focused strategies (i.e., positive reframing, acceptance, religion, using emotional support, and denial). The $\mathrm{KMO}(\mathrm{KMO}=.762)$ and Bartlett's test of sphericity $(\mathrm{X} 2=6022.79, \mathrm{df}=435, \mathrm{p}<.001)$ indicated that the set of variables were at least adequately related for factor analysis. The analysis revealed a two-factor structure, i.e., a problem-focused and an emotion-focused factor. Two scales were constructed according to the two factors that emerged: (i) an emotion-focused scale formed by summing over items $1,6,7,8,10,13,19,20,21,25$, and 28 (the full strategies were emotional social support, instrumental social support, restraint, venting of emotion, and substance use) and (ii) a problem-focused scale formed by summing over items $2,12,14,15,16,17$, and 26 (the full strategies were active coping, planning and positive reinterpretation).

Instrumental support is usually not considered a contributing factor to emotion-focused coping. However, in the context of a global pandemic associated with great uncertainty and a lack of understanding, it is likely that people may have responses and ideas similar to their peers. In such a situation, turning to others might provide emotional relief.

\section{Optimism}

The Life Orientation Test (LOT) is a self-report questionnaire that assesses generalized expectations of the occurrence of good outcomes in one's life. The questionnaire administered was the Hebrew version of the optimism scale developed by Scheier and Carver (Zimet et al., 1988). Participants are asked to indicate their relative agreement with six items on a scale ranging from 0 (do not agree at all) to 4 (very much agree). A sample item is "I always look on the bright side of things." In the current sample, the internal consistency was $\alpha=.809$.

\section{Gratitude}

The Gratitude questionnaire is a self-report questionnaire that evaluates the tendency to recognize and respond to positive feelings of appreciation. It is also directed toward the role played by the generosity of others in one's experiences and individuals' sense of achievement (Emmons et al., 2003). The questionnaire administered was a version of the gratitude scale developed by McCullough, Emmons, and Tsang (McCullough et al., 2002) and translated into Hebrew (Israel-Cohen et al., 2015). It contains six items, where participants are asked to rate the extent to which they agree with the statement on a scale ranging from 1 (do not agree at all) to 7 (very much agree). For example, a sample item is "I have so much in life to be thankful for." The Cronbach's alpha as reported by the developers was .82 (Emmons et al., 2003). In the current sample, the internal consistency was $\alpha=.737$.

\section{Data Analysis}

SPSS 26.0 for Windows was used for the statistical analysis of the data. Categorical data were expressed as numbers and percentages and quantitative data as the mean \pm standard deviation $(S D)$. To test whether the sociodemographic factors associated with the main study variables, we used t-tests, as well as Pearson and Spearman correlation as appropriate. The Pearson correlation was used to test the correlations for the quantitative variables. In order to analyze the Cope questionnaire, principal component factor analysis with Varimax rotation was applied. Items were assigned to factors on which they loaded at .4 or more. To predict depression and anxiety, two multiple regression analyses were conducted, each consisting of a two-step block: the first block included the sociodemographic factors (age, gender, SES) and was entered as a forced-entry block. The second block included five variables that were entered in a stepwise manner: emotion-focus 
strategy, problem-focus strategy, life orientation (optimism), gratitude, and social support.

\section{Results}

\section{Demographic Characteristics}

Overall, 655 participants were included in this study. The demographic characteristics are listed in Table 1.

\section{Depression and Anxiety Levels}

Overall, the mean GAD-7 score was $4.21 \pm 4.14$ (ranging from 0 to 21). It broke down into 402 (61.4\%) non-anxious, $183(27.9 \%)$ mildly anxious, 50 (7.6\%) moderately anxious, and $20(3.1 \%)$ severely anxious responses. Based on the GAD-9 scoring criteria, 568 (86.5\%) of the participants were classified into the non-anxiety group and $87(13.2 \%)$ into the anxiety group.For the PHQ-9 questionnaire, the mean score was $6.1 \pm 5.27$ (ranging from 0 to 27). This broke down into $305(46.4 \%)$ non-depressed, $212(32.3 \%)$ mildly depressed, $121(18.5 \%)$ moderately depressed, and 17 (2.6\%) severely depressed. Based on the PHQ scoring criteria, 517 (78.7\%) fell into the non-depressed group, and 138 (21.3\%) were classified into the depressed group. There was a significant correlation between the GAD-7 and the PHQ-9 $r=.713(p<.001)$.

\section{Associations Between Sociodemographic Factors, Anxiety, and Depression}

To examine the relationship between sociodemographic variables and the GAD-7 anxiety score, several tests were used. For gender, the independent-samples t-test results showed higher anxiety scores among females $(M=4.92, S D=4.29)$ than males $(M=3.03, S D=3.80, \mathrm{t}(653)=-5.9 \mathrm{p}<001)$. A Pearson correlation test for age indicated a negative correlation between age and anxiety $(r(653)=-.204, p<.001)$, indicating that older people tended to be less anxious. To examine SES, a Spearman correlation test indicated a negative correlation between SES and anxiety $(p=-.194 p<.001)$. To examine the relationship between sociodemographic variables and the PHQ depression score, several tests were used. An independent-samples t-test for gender indicated a higher anxiety score for females $(M=6.82, S D=5.20)$ than for males $(M=4.91, S D=5.17, t(653)=-4.56 p<.001)$. A Pearson correlation test for age indicated a negative correlation between age and depression $(r(653)=-.30, p<.001)$. A Spearman correlation test for SES showed a negative correlation between socioeconomic status and depression $(p=-.263 p<.001)$.

\section{Factors Effecting Anxiety and Depression}

The mean Gratitude score was 34.16 \pm 5.31 (ranging from 10 to 42), the mean Life Orientation Test score was $2.59 \pm 0.69$ (ranging from 0.17 to 4 ), and the mean Social Support test score was $5.83 \pm 1.05$ (ranging from 1.42 to 7 ). All these factors were correlated to depression and anxiety, as shown in Table 2.

\section{COPE-Coping Behavior Questionnaire}

Table 3 lists the mean scores for coping strategies and the correlations between coping strategies, anxiety, and depression. Active coping, positive interpretation and growth, planning, and accepting the situation were negatively correlated with depression and anxiety. The factor analysis loadings are shown in Table 4.

\section{Regression Analysis Predicting Anxiety and Depression}

Combined into a regression model, the results were significant and accounted for approximately $34.9 \%$ of the variance in the GAD scores and $40.5 \%$ of the variance in the PHQ scores. Both models included all the factors mentioned above except gratitude when predicting depression, and optimism, which was not significant when predicting anxiety. The regression results are shown in Table 5.

\section{Additional Analyses}

To better understand the findings on the association between age and depression/anxiety, further correlational analyses were conducted. First, the association between age and media consumption (assessed via the sociodemographic questionnaire: see Appendix) was subjected to a Spearman test. This was found to be significant and positive $(r=.220, p<.01)$. The second correlation was between resources and depression/ anxiety and was found to be significant and negative ( $r=$ $-.295, p<.01 ; r=-.252 p<.001$, respectively). Tests of partial correlations between age and depression/anxiety when controlling for resources revealed a weaker significant correlation $(r=.258, p<.001 ; r=-.155 p<.01$, respectively). The third correlation between age and emotion-focused strategy was found to be significant and negative $(r=-.253, p<.001)$.

\section{Discussion}

Both anxiety and depression are frequent forms of psychological distress in normal situations and especially during crises. The current findings indicate that during the first wave of the pandemic in Israel, $21.3 \%$ of the general population in Israel appeared to have suffered from mild to severe depression and 
Table 2. Pearson correlations for the questionnaires $(\mathrm{N}=655)$

\begin{tabular}{|c|c|c|c|c|c|}
\hline & $\begin{array}{l}\text { PHQ- } \\
9\end{array}$ & $\begin{array}{l}\text { GAD- } \\
7\end{array}$ & Life Orientation Test & MSPSS & Gratitude \\
\hline PHQ-9 & & $.713^{* *}$ & $-.340 * *$ & $-.201 * *$ & $-.227 * *$ \\
\hline GAD-7 & & & $-.315 * *$ & $-.176^{* *}$ & $-.203 * *$ \\
\hline Life Orientation Test & & & & $.240 * *$ & $.458 * *$ \\
\hline MSPSS & & & & & $.370 * *$ \\
\hline Gratitude & & & & & \\
\hline
\end{tabular}

PHQ-9, depression; GAD-7, anxiety; MSPSS, social support; Life Orientation Test, optimism

$* * \mathrm{p}<0.001$
$13.2 \%$ from mild to severe anxiety. A comparison of these findings with the rates of depression and anxiety in nonpandemic periods revealed no major differences. Previous findings on the Israeli population reported that the percentage of depression for 2015-2017 ranged from $27.2 \%$ to $23 \%$, respectively (Central Bureau of Statistics, 2019). In addition, in a study conducted in 2004, 9.7\% reported a mood or an anxiety disorder during that year (Levinson et al., 2007). This might be related to the generally high level of tension in the Middle East associated with the geopolitical and security context (e.g., missile attacks, terror attacks, and wars). It is possible that these unique conditions have caused the Israeli population to develop a form of resilience. However, this resilience could be challenged or eroded during a long-lasting pandemic. This can be viewed as similar to the way the human body handles stress. In the initial acute stage, the body handles the stress and returns to health rather quickly. However, this resilience can be depleted over time and can manifest in fatigue from the constant need to cope, which may make people more susceptible to depression and anxiety (McGonagle \& Kessler, 1990). Other Israeli reports have indicated an increase of $8 \%$ in anxiety and an increase of $4 \%$ in depression between the first wave and the second wave during the month of July 2020 (Central Bureau of Statistics, 2020).

This study examined whether the risks and protective factors found to be strongly related to depression and anxiety under ordinary circumstances would also be predictive during the COVID-19 pandemic. Specifically, the relative contribution of each factor in predicting depression and anxiety was examined while controlling for sociodemographic factors.

As hypothesized, three factors emerged as protective and decreased the likelihood of reporting symptoms of depression.
Table 3. Correlations between coping strategies, anxiety, and depression $(\mathrm{N}=655)$

\begin{tabular}{|c|c|c|c|c|c|c|}
\hline \multirow[t]{2}{*}{ Coping strategy } & \multirow[t]{2}{*}{ Mean } & \multirow[t]{2}{*}{$\mathrm{SD}$} & \multicolumn{2}{|l|}{ PHQ } & \multicolumn{2}{|l|}{ GAD } \\
\hline & & & $\mathrm{R}$ & Sig. & $\mathrm{R}$ & Sig. \\
\hline Restraint & 2.57 & 0.83 & $.237 * *$ & $<.001$ & $.169 * *$ & $<.001$ \\
\hline Active coping & 3.51 & 0.08 & $-.109 * *$ & .005 & .036 & .356 \\
\hline Denial & 1.74 & 0.72 & $.218 * *$ & $<.001$ & $.239 * *$ & $<.001$ \\
\hline Substance use & 1.55 & 0.72 & $.383 * *$ & $<.001$ & $.321 * *$ & $<.001$ \\
\hline Acceptance & 3.61 & 0.86 & $-.079 * *$ & $<.001$ & $-.135^{* *}$ & $<.001$ \\
\hline Religion & 1.95 & 0.93 & .013 & .738 & .010 & .808 \\
\hline Planning & 3.57 & 0.81 & $-.206 * *$ & $<.001$ & $-.145^{* *}$ & $<.001$ \\
\hline Humor & 2.96 & 1.01 & .054 & .159 & .040 & .319 \\
\hline Venting of emotion & 2.21 & 1.00 & $.598 * *$ & $<.001$ & $.616^{* *}$ & $<.001$ \\
\hline Positive reframing & 3.64 & 0.82 & $-.131 * *$ & .001 & -.061 & .118 \\
\hline Emotional support & 3.21 & 1.01 & $.183 * *$ & $<.001$ & $.211 * *$ & $<.001$ \\
\hline Instrumental support & 2.30 & 0.96 & $.158 * *$ & $<.001$ & $.232 * *$ & $<.001$ \\
\hline Mental disengagement & 2.87 & 0.91 & $.332 * *$ & $<.001$ & $.235 * *$ & $<.001$ \\
\hline Behavioral disengagement & 2.42 & 0.85 & $.288 * *$ & $<.001$ & $.201 * *$ & $<.001$ \\
\hline Suppression of competing activities & 1.74 & 0.72 & .040 & .306 & .054 & .166 \\
\hline Emotion-focused & 1.55 & 0.72 & $.480 * *$ & $<.001$ & $.494 * *$ & $<.001$ \\
\hline Problem-focused & 3.61 & 0.86 & $-.178 * *$ & $<.001$ & $-.098 * *$ & .011 \\
\hline
\end{tabular}

$* * p<0.001$ 
Table 4. Coping questionnaire item loadings $(\mathrm{N}=655)$

Item

I've been trying to get advice or help from other people about what to do

I've been looking for something good in what is happening

I put my trust in God

I turn to work or other substitute activities to take my mind off things

I admit to myself that I can't deal with it, and quit trying

I refuse to believe that it has happened

I force myself to wait for the right time to do something

I've been using alcohol or other drugs to make myself feel better

I've been making jokes about it

I feel a lot of emotional distress and I find myself expressing those feelings a lot

I learn to live with it

I try hard to prevent other things from interfering with my efforts at dealing with this

I try to get emotional support from friends or relatives

I think about how I might best handle the problem

I do what has to be done, one step at a time

I concentrate my efforts on doing something about it

I make a plan of action

I accept that this has happened and that it can't be changed

I get upset, and am really aware of it

I talk to someone about how I feel

I put aside other activities in order to concentrate on this

I reduce the amount of effort I ' $\mathrm{m}$ putting into solving the problem

I sleep more than usual

I pray more than usual

I talk to someone who could do something concrete about the problem

I learn something from the experience

I've been making fun of the situation

I ' ve been using alcohol or other drugs to help me get through it

I restrain myself from doing anything too quickly

I act as though it hasn't even happened

$\%$ of the variance
Factor 1:

Emotion-focused strategy

.524

$-.029$

.068

.391

.391

.479

.516

.498

.295

.713

$-.210$

.193

.576

.002

$-.110$

.269

$-.079$

$-.056$

.740

.436

.447

.338

.286

.231

.502

.079

.153

.518

.383

.086

14.410
Factor 2:

Problem-focused strategy

.195

.542

.141

.284

$-.055$

$-.143$

.076

$-.170$

.271

$-.106$

.372

.460

.406

.728

.692

.574

.594

.172

$-.156$

.359

.295

.008

$-.081$

.066

.242

.610

.325

$-.183$

.242

$-.246$

12.505

Table 5. Multiple regression predicting depression and anxiety $(\mathrm{N}=655)$

\begin{tabular}{|c|c|c|c|c|c|c|c|c|c|c|}
\hline \multirow[b]{2}{*}{ Variable } & \multicolumn{5}{|l|}{ PHQ-9 } & \multicolumn{5}{|c|}{ GAD-7 } \\
\hline & $B$ & $\beta$ & $\mathrm{T}$ & Model Sig. & $\mathrm{R}^{2}$ & $B$ & $\beta$ & $\mathrm{T}$ & Model Sig. & $\mathrm{R}^{2}$ \\
\hline Gender & .967 & $.089 * *$ & 2.714 & $<.001$ & .160 & 1.006 & $.117 * *$ & 3.483 & $<.001$ & .113 \\
\hline Age & -.052 & $-.148 * *$ & -4.395 & & & -.013 & -.046 & -1.315 & & \\
\hline Socioeconomic status & -1.189 & $-.138 * *$ & -4.159 & & & -.675 & $-.100 * *$ & -2.877 & & \\
\hline Emotion-focused strategy & 3.778 & $.437 * *$ & 12.822 & $<.001$ & .141 & 2.998 & $.441 * *$ & 11.991 & $<.001$ & .164 \\
\hline Problem-focused strategy & -1.812 & $-.219 * *$ & -6.593 & $<.001$ & .066 & -.932 & $-.143 * *$ & -3.999 & $<.001$ & .037 \\
\hline Social support & -.835 & $-.167 * *$ & -5.034 & $<.001$ & .033 & -.611 & $-.155^{* *}$ & -4.605 & $<.001$ & .028 \\
\hline Life Orientation Test & & & & & & -.538 & -.091 & -2.45 & $<.001$ & .006 \\
\hline Gratitude & -.073 & -.073 & -2.098 & $<.001$ & .004 & & & & & \\
\hline
\end{tabular}

$* * p<0.01$ 
One was a problem-focused strategy. It is likely that its positive effect increased the respondents' sense of control and reduced uncertainty since individuals channeled efforts toward practical solutions and specific goals. This was reflected in efforts to maintain a routine when everyday life activities had been blocked by the stay-at-home order. It is possible that recreating a daily routine within this type of a situation allowed people to feel a certain sense of control by taking practical steps to produce a plan of action in stages to deal with the situation.

Another protective factor was social support. The pandemic and its social distancing regulations created individuals' sense of loneliness that may have highlighted the need for social interactions. In these circumstances, social support functioned as another way of achieving a sense of belonging and love but also as a basis for comfort and a feeling of solidarity and common fate.

Both models included gratitude or optimism as a protective factor. Since both definitions have several features in common (Wood et al., 2008; Wood et al., 2011; Scheier \& Carver, 1985), it is not surprising that a medium-high correlation was found in the present study.

The results also showed that sociodemographic factors increased the likelihood of the manifestation of depression and anxiety. Women and people self-identifying as having low SES tended to suffer more from symptoms of depression and anxiety. The findings for age during COVID-19 differed from ordinary circumstances and showed that young adults suffered from more depression and anxiety symptoms than older people (Huang \& Zhao, 2020; Losada-Baltar et al., 2020).

Since the highest mortality rate has been found among the elderly during the pandemic (Weinreb \& Chernichovsky, 2020), it is notable that this group was found to be less psychologically impacted. Qiu et al. (Huang \& Zhao, 2020) suggested that this could be related to the massive exposure to COVID-19 related information (via multiple media channels) in younger people as compared to more moderate media consumption by the elderly. However, in the present study, the results revealed an opposite correlation between age and the amount of news consumption, where the elderly consumed more news. Another plausible explanation could be the substantial disparity in financial resources between groups. The findings indicated that older people had more financial resources. Resources are likely to impact individuals' mental state during periods of uncertainty caused by a financial crisis and may hinder effective functioning in other areas of life (work, family, relationship) (Silva et al., 2020; Johnson et al., 2020). Another possible explanation is related to the life experiences generally associated with the elderly, which may account for overall better coping with stressful events (Wang et al., 2021). This could clarify the negative correlation between age and the emotion-focused strategy. Therefore, it is plausible that a decreased use of this strategy could contribute to the better mental state and wellbeing observed in the elderly population.

Furthermore, the emotion-focused strategy was found to be a major predictor of depression and anxiety. In the context of the COVID-19 pandemic, an emotion-focused strategy may be considered maladaptive since it centers a person's attention and thoughts around major difficulties and uncertainty and can also lead to a sense of helplessness. This may also prompt ruminative behavior (Van Berkel, 2009; Ray et al., 1982) and may help explain the strong correlation between depression/ anxiety and the emotion-focused strategy in the analysis.

As discussed, young people tended to be the age group experiencing the greatest depression and anxiety. In addition, the emotion-focused strategy was the most influential risk factor and was found to be utilized to a greater extent in the younger respondents. This suggests that services should be created such as dedicated websites and mobile apps that can help provide a first response and reduce depression and anxiety by promoting active coping such as planning a daily routine. We believe that implementing these techniques could help individuals channel their efforts toward problemfocused coping.

There are a number of limitations to this study. Due to the use of snowball sampling, the sample was characterized by its relatively high socioeconomic status, and therefore, might be biased. This could impact the rates of depression and anxiety, as it might be associated with the sample's greater wherewithal to deal with the crisis. In addition, the data were collected via an Internet questionnaire, which could have been technically challenging for the elderly, who are generally considered less accustomed to using computers.

It should be noted that the factor analysis findings did not fully correspond with the original division of the coping strategies (only eight items loaded onto their original factor). However, division into types of strategies has also yielded inconclusive results in the literature. Previous studies have reported different factors for different populations (Schoenmakers et al., 2015; McLoughlin, 2019; Ersahin, 2020). Specifically, when this questionnaire was administered in Israel, it yielded a different factor structure than the original questionnaire (Ben-Zur \& Yagil, 2005; Ben-Zur et al., 2001). Considering all the above, we believe that the division into two main coping strategies nevertheless helps shed light on the ways individuals cope with this situation but should be interpreted with caution.

Future studies could examine the impact of coping strategies over time, by exploring whether coping strategies change as a function of waves and whether coping styles affect anxiety and depression differently in the long term. 


\section{Appendix. Sociodemographic and Personal Questionnaire}

1. How old are you?

2. What is your gender? (man/woman/other)

3. What is your marital status? (single/in relationship/married/separated/divorced/widowed/other)

4. How many children do you have? $(0 / 1 / 2 / 3 / 4$ or more)

5. What is your level of education? (12 years or less, without diploma/12 years with diploma/B.A./M.A. or higher/ other)

6. What is your occupation? (office job/physical job/housewife/retired unemployed/other)

7. What is your socioeconomic status? (low/low-average/ average/average-high/high)

8. What is your level of religious observance? (secular/traditional/ultraorthodox)

9. Do you have any medical or functional restrictions/disabilities? If yes, please specify (yes/no)

10. Are you currently on medication for a chronic condition? (yes/no)

11. Do you have a previous history of depression/anxiety? (yes/no)

12. Have you taken antidepressants or tranquilizers in the past? (yes/no)

13. What is your current state of health? (healthy/healthy but in quarantine/diagnosed with COVID-19 currently in quarantine/have another disease)

14. Do you know people diagnosed with COVID-19? (yes/ no)

15. If you know people diagnosed with COVID-19, what is the severity of the disease from 1 (not severe at all) to 10 (very severe)? If you know more than one person, please refer to the person closest to you.

16. If you know people diagnosed with COVID-19, what is the degree of proximity from 1 (not close at all) to 10 (very close)? If you know more than one person, please refer to the one you consider the closest to you.

17. Do you know someone who has died of COVID-19? (yes/no)

18. What is your occupational status as a result of the COVID-19? (full time job/partially employed/unpaid vacation/lost my job/unemployed/retired)

19. In your opinion, what are your chances of returning to your previous field of activity after the current crisis? (very likely/somewhat likely/not very likely)

20. Are the financial resources available to you sufficient for the next 3 months? (not enough at all/hardly enough/ enough/definitely enough/my resources will suffice for the next 3 months but not for a year)

21. On average, how many hours a day do you spend on media news updates (TV/Radio/Internet)? (none at all/1 $\mathrm{h}$ or less $/ 1-2 \mathrm{~h} / 2-3 \mathrm{~h} /$ more than $3 \mathrm{~h}$ )
22. Did you exercise regularly prior to the lockdown? (yes/ no)

23. Have you kept up your exercise regime at home during COVID-19? (yes/no)

Availability of Data and Material On demand Code Availability Not applicable

Author's Contribution OE supervised the study and wrote the manuscript with both her students: $\mathrm{ZO}$ and $\mathrm{AA} ; \mathrm{ZO}$ and AA collected the data and analyzed the data; SL assisted in the statistical analyses and writing the results section; EK helped design the protocol. All the authors read and approved the final version of the manuscript and agree with the order of presentation of the authors.

Data Availability All data generated or analyzed during this study are included in this article (and its Appendix information files).

The datasets generated during and/or analyzed during the current study are available from the corresponding author on reasonable request.

\section{Declarations}

Ethical Standards This study was approved by the appropriate ethics committee and was conducted in accordance with the ethical standards laid down in the 1964 Declaration of Helsinki and its later amendments.

All participants gave their informed consent prior to inclusion in the study.

Conflict of Interest There authors declare no competing interests.

\section{References}

Baker, J. P., \& Berenbaum, H. (2007). Emotional approach and problemfocused coping: A comparison of potentially adaptive strategies. Cognition and Emotion, 21(1), 95-118.

Ben-Zur, H., \& Yagil, D. (2005). The relationship between empowerment, aggressive behaviours of customers, coping, and burnout. European Journal of work and organizational psychology, 14(1), 81-99.

Ben-Zur, H., \& Zeidner, M. (1995). Coping patterns and affective reactions under community crisis and daily routine conditions. Anxiety, stress, and coping, 8(3), 185-201.

Ben-Zur, H., Gilbar, O., \& Lev, S. (2001). Coping with breast cancer: Patient, spouse, and dyad models. Psychosomatic Medicine, 63(1), 32-39.

Bleich, A., Gelkopf, M., Melamed, Y., \& Solomon, Z. (2006). Mental health and resiliency following 44 months of terrorism: A survey of an Israeli national representative sample. BMC medicine, 4(1), 21.

Bozo, Ö., Demirtepe-Saygıll, D., Güneș, S., Çenesiz, G. Z., \& Baysan, A. (2018). Does problem focused coping buffer the effects of trait anxiety on depressive symptoms of chronic urticaria patients? The Journal of general psychology, 145(1), 64-78.

Cao, W., Fang, Z., Hou, G., Han, M., Xu, X., Dong, J., \& Zheng, J. (2020). The psychological impact of the COVID-19 epidemic on college students in China. Psychiatry research, 112934.

Carver, C. S., Scheier, M. F., \& Weintraub, J. K. (1989). Assessing coping strategies: A theoretically based approach. Journal of personality and social psychology, 56(2), 267-283.

Central Bureau of Statistics (2019). Well-being, Sustainability, and National Resilience Indicators. Jerusalem 
Central Bureau of Statistics (2020). Civil Resilience during the coronavirus crisis, findings from a follow-up survey. Jerusalem

Cheng, C., \& Tang, C. S. K. (2004). The psychology behind the masks: Psychological responses to the severe acute respiratory syndrome outbreak in different regions. Asian Journal of Social Psychology, 7(1), 3-7.

Chesney, E., Goodwin, G. M., \& Fazel, S. (2014). Risks of all-cause and suicide mortality in mental disorders: A meta-review. World psychiatry, 13(2), 153-160.

Christensen, M. V., \& Kessing, L. V. (2005). Clinical use of coping in affective disorder, a critical review of the literature. Clinical practice and epidemiology in mental health, 1(1), 20.

Conversano, C., Rotondo, A., Lensi, E., Della Vista, O., Arpone, F., \& Reda, M. A. (2010). Optimism and its impact on mental and physical well-being. Clinical practice and epidemiology in mental health: $C P \& E M H, 6,25-29$.

Emmons, R. A., \& Stern, R. (2013). Gratitude as a psychotherapeutic intervention. Journal of clinical psychology, 69(8), 846-855.

Emmons, R. A., McCullough, M. E., \& Tsang, J. A. (2003). The assessment of gratitude.

Ersahin, Z. (2020). Post-traumatic growth among Syrian refugees in Turkey: The role of coping strategies and religiosity. Current Psychology, 1-10.

Folkman, S., \& Lazarus, R. S. (1984). Stress, appraisal, and coping (pp. 150-153). Springer Publishing Company.

Folkman, S., \& Moskowitz, J. T. (2000). Positive affect and the other side of coping. American psychologist, 55(6), 647-654.

Gariepy, G., Honkaniemi, H., \& Quesnel-Vallee, A. (2016). Social support and protection from depression: systematic review of current findings in Western countries. The British Journal of Psychiatry, 209(4), 284-293.

Geulayov, G., Jungerman, T., Moses, S., Friedman, N., Miron, R., \& Gross, R. (2009). Validation of the Hebrew version of the PHQ-9, a screening instrument for depression in primary care. Isr $J$ Psychiatry, 46, 45.

Grav, S., Hellzèn, O., Romild, U., \& Stordal, E. (2012). Association between social support and depression in the general population: The HUNT study, a cross-sectional survey. Journal of clinical nursing, 21(1-2), 111-120.

Hidaka, B. H. (2012). Depression as a disease of modernity: Explanations for increasing prevalence. Journal of affective disorders, 140(3), 205-214.

Hinz, A., \& Brähler, E. (2011). Normative values for the hospital anxiety and depression scale (HADS) in the general German population. Journal of psychosomatic research, 71(2), 74-78.

Hinz, A., \& Schwarz, R. (2001). Anxiety and depression in the general population: Normal values in the Hospital Anxiety and Depression Scale. Psychotherapie, Psychosomatik, medizinische Psychologie, 51(5), 193-200.

Hobfoll, S. E., Lomranz, J., Eyal, N., Bridges, A., \& Tzemach, M. (1989). Pulse of a nation: Depressive mood reactions of Israelis to the IsraelLebanon War. Journal of Personality and Social Psychology, 56(6), 1002-1012.

Huang, Y., \& Zhao, N. (2020). Generalized anxiety disorder, depressive symptoms and sleep quality during COVID-19 outbreak in China: A web-based cross-sectional survey. Psychiatry Research, 112954

Hudson, D. L., Neighbors, H. W., Geronimus, A. T., \& Jackson, J. S. (2012). The relationship between socioeconomic position and depression among a US nationally representative sample of African Americans. Social Psychiatry and Psychiatric Epidemiology, 47(3), 373-381.

Israel-Cohen, Y., Uzefovsky, F., Kashy-Rosenbaum, G., \& Kaplan, O. (2015). Gratitude and PTSD symptoms among Israeli youth exposed to missile attacks: Examining the mediation of positive and negative affect and life satisfaction. The Journal of Positive Psychology, 10(2), 99-106.
Johansson, R., Carlbring, P., Heedman, Å., Paxling, B., \& Andersson, G. (2013). Depression, anxiety and their comorbidity in the Swedish general population: Point prevalence and the effect on health-related quality of life. PeerJ, 1, e98.

Johnson, M., Johnson, E., Webber, L., \& Nettle, D. (2020). Mitigating social and economic sources of trauma: The need for universal basic income during the coronavirus pandemic. Psychological Trauma: Theory, Research, Practice, and Policy.

Kroenke, K., Spitzer, R. L., \& Williams, J. B. (2001). The PHQ-9: Validity of a brief depression severity measure. Journal of general internal medicine, 16(9), 606-613.

Lambert, N. M., Fincham, F. D., \& Stillman, T. F. (2012). Gratitude and depressive symptoms: The role of positive reframing and positive emotion. Cognition \& Emotion, 26(4), 615-633.

Lazarus, R. S. (1999). Stress and emotion: A new synthesis. Springer.

Levinson, D., Zilber, N., Lerner, Y., Grinshpoon, A., \& Levav, I. (2007). Prevalence of mood and anxiety disorders in the community: Results from the Israel National Health Survey. Israel Journal of Psychiatry and Related Sciences, 44(2), 94.

Losada-Baltar, A., Jiménez-Gonzalo, L., Gallego-Alberto, L., PedrosoChaparro, M. D. S., Fernandes-Pires, J., \& Márquez-González, M. (2020). "We're staying at home". Association of self-perceptions of aging, personal and family resources and loneliness with psychological distress during the lock-down period of COVID-19. The Journals of Gerontology: Series B.

Löwe, B., Decker, O., Müller, S., Brähler, E., Schellberg, D., Herzog, W., \& Herzberg, P. Y. (2008). Validation and standardization of the Generalized Anxiety Disorder Screener (GAD-7) in the general population. Medical care, 266-274

Manea, L., Gilbody, S., \& McMillan, D. (2012). Optimal cut-off score for diagnosing depression with the Patient Health Questionnaire (PHQ9): a meta-analysis. Cmaj, 184(3), E191-E196.

Marroquín, B. (2011). Interpersonal emotion regulation as a mechanism of social support in depression. Clinical psychology review, 31(8), 1276-1290.

Matthieu, M. M., \& Ivanoff, A. (2006). Using stress, appraisal, and coping theories in clinical practice: Assessments of coping strategies after disasters. Brief Treatment and Crisis Intervention, 6(4), 337 348.

McCullough, M. E., Emmons, R. A., \& Tsang, J. A. (2002). The grateful disposition: A conceptual and empirical topography. Journal of personality and social psychology, 82(1), 112-127.

McGonagle, K. A., \& Kessler, R. C. (1990). Chronic stress, acute stress, and depressive symptoms. American journal of community psychology, 18(5), 681-706.

McGuire, A. P., Gauthier, J. M., Anderson, L. M., Hollingsworth, D. W., Tracy, M., Galea, S., \& Coffey, S. F. (2018). Social support moderates effects of natural disaster exposure on depression and posttraumatic stress disorder symptoms: effects for displaced and nondisplaced residents. Journal of traumatic stress, 31(2), 223-233.

McLoughlin, L. T. (2019). Understanding and measuring coping with cyberbullying in adolescents: Exploratory factor analysis of the brief coping orientation to problems experienced inventory. Current Psychology, 1-11.

Mykletun, A., Bjerkeset, O., Dewey, M., Prince, M., Overland, S., \& Stewart, R. (2007). Anxiety, depression, and cause-specific mortality: The HUNT study. Psychosomatic medicine, 69(4), 323-331.

Newman, M. G., Zuellig, A. R., Kachin, K. E., Constantino, M. J., Przeworski, A., Erickson, T., \& Cashman-McGrath, L. (2002). Preliminary reliability and validity of the Generalized Anxiety Disorder Questionnaire-IV: A revised self-report diagnostic measure of generalized anxiety disorder. Behavior Therapy, 33(2), 215-233.

Qiu, J., Shen, B., Zhao, M., Wang, Z., Xie, B., \& Xu, Y. (2020). A nationwide survey of psychological distress among Chinese people in the COVID-19 epidemic: Implications and policy recommendations. General psychiatry, 33(2), e100213. 
Rajkumar, R. P. (2020). COVID-19 and mental health: A review of the existing literature. Asian journal of psychiatry, 102066.

Ray, C., Lindop, J., \& Gibson, S. (1982). The concept of coping. Psychological Medicine, 12(2), 385-395.

Roohafza, H., Feizi, A., Afshar, H., Mazaheri, M., Behnamfar, O., Hassanzadeh-Keshteli, A., \& Adibi, P. (2016). Path analysis of relationship among personality, perceived stress, coping, social support, and psychological outcomes. World journal of psychiatry, 6(2), 248-256.

Salehi, H., Simbar, M., Abolghasemi, A., \& Abadi, A. (2013). A comparison of postpartum depression among low-risk-pregnant women with emotion-and problem-focused coping strategies. Qom University of Medical Sciences Journal, 7(2), 35-40.

Scheier, M. F., \& Carver, C. S. (1985). Optimism, coping, and health: Assessment and implications of generalized outcome expectancies. Health psychology, 4(3), 219-247.

Schoenmakers, E. C., van Tilburg, T. G., \& Fokkema, T. (2015). Problem-focused and emotion-focused coping options and loneliness: How are they related? European Journal of Ageing, 12(2), 153-161.

Silva, M., Resurrección, D. M., Antunes, A., Frasquilho, D., \& Cardoso, G. (2020). Impact of economic crises on mental health care: a systematic review. Epidemiology and psychiatric sciences, 29.

Sirois, F. M., \& Wood, A. M. (2017). Gratitude uniquely predicts lower depression in chronic illness populations: A longitudinal study of inflammatory bowel disease and arthritis. Health Psychology, 36(2), $122-132$.

Spitzer, R. L., Kroenke, K., Williams, J. B., \& Patient Health Questionnaire Primary Care Study Group, \& Patient Health Questionnaire Primary Care Study Group. (1999). Validation and utility of a self-report version of PRIME-MD: The PHQ primary care study. Jama, 282(18), 1737-1744.

Spitzer, R. L., Kroenke, K., Williams, J. B., \& Löwe, B. (2006). A brief measure for assessing generalized anxiety disorder: the GAD-7. Archives of internal medicine, 166(10), 1092-1097.

Stordal, E., Bjartveit Krüger, M., Dahl, N. H., Krüger, Ø., Mykletun, A., $\&$ Dahl, A. A. (2001). Depression in relation to age and gender in the general population: The Nord-Trøndelag Health Study (HUNT). Acta Psychiatrica Scandinavica, 104(3), 210-216.
Van Berkel, H. K. (2009). The relationship between personality, coping styles and stress, anxiety and depression

Viseu, J., Leal, R., de Jesus, S. N., Pinto, P., Pechorro, P., \& Greenglass, E. (2018). Relationship between economic stress factors and stress, anxiety, and depression: Moderating role of social support. Psychiatry research, 268, 102-107.

Wang, J. L., Schmitz, N., \& Dewa, C. S. (2010). Socioeconomic status and the risk of major depression: the Canadian National Population Health Survey. Journal of Epidemiology \& Community Health, 64(5), 447-452.

Wang, C., Pan, R., Wan, X., Tan, Y., Xu, L., Ho, C. S., \& Ho, R. C. (2020). Immediate psychological responses and associated factors during the initial stage of the 2019 coronavirus disease (COVID-19) epidemic among the general population in China. International journal of environmental research and public health, 17(5), 1729.

Wang, Y., Di, Y., Ye, J., \& Wei, W. (2021). Study on the public psychological states and its related factors during the outbreak of coronavirus disease 2019 (COVID-19) in some regions of China. Psychology, health \& medicine, 26(1), 13-22.

Weinreb, A., \& Chernichovsky, D. (2020). Anticipating the total mortality impact of coronavirus in Israel.

Wood, A. M., Maltby, J., Stewart, N., \& Joseph, S. (2008). Conceptualizing gratitude and appreciation as a unitary personality trait. Personality and individual differences, 44(3), 621-632.

Wood, A. M., Brown, G. D., \& Maltby, J. (2011). Thanks, but I'm used to better: A relative rank model of gratitude. Emotion, 11(1), 175-180.

Zeidner, M., \& Ben-Zur, H. (1993). Coping with a national crisis: The Israeli experience with the threat of missile attacks. Personality and Individual Differences, 14(1), 209-224.

Zhang, J., Lu, H., Zeng, H., Zhang, S., Du, Q., Jiang, T., \& Du, B. (2020). The differential psychological distress of populations affected by the COVID-19 pandemic. Brain, Behavior, and Immunity.

Zimet, G. D., Dahlem, N. W., Zimet, S. G., \& Farley, G. K. (1988). The multidimensional scale of perceived social support. Journal of personality assessment, 52(1), 30-41.

Publisher's Note Springer Nature remains neutral with regard to jurisdictional claims in published maps and institutional affiliations. 